\title{
Artan Dozlarda Bor Uygulamasının İki Farklı Zeytin (Olea europaea L.) Çeşidinin Yaprak Bor Konsantrasyonu Üzerine etkisi
}

\author{
Sadettin BOZGEYİK ${ }^{1}$, Ayfer Alkan TORUN ${ }^{1 *}$
}

\section{ÖZ}

Zeytin (Olea europaea L.) bor (B) noksanlığına karşı duyarlı bir bitki olup, B noksanlığ zeytinde verim ve kaliteyi önemli oranda etkilemektedir. Dünyada ve Türkiye'de zeytinde B noksanlığına sık rastlanmaktadır. Bu çalışmada 2 zeytin çeşidine artan dozlarda yapraktan $\mathrm{B}$ uygulamalarının etkisi incelenmiştir. Bu amaçla yürütülen denemede, Ayvalık ve Gemlik zeytin çeşitlerine som (çiçek açmadan önceki dönem) ve meyvelerin nohut büyüklüğünde olduğu iki farklı dönemde artan dozlarda of $\mathrm{H}_{3} \mathrm{BO}_{3}(\% 0 ; \% 0.2 ; \% 0.4 ; \% 0.6$ ve \%0.8) yapraktan uygulanarak çeşitlerin, yaprak $\mathrm{B}$ ve diğer besin elementi konsantrasyonları belirlenmiştir. Elde edilen sonuçlara göre; artan dozlarda B uygulaması ile her iki çeşidin yaprağındaki $\mathrm{B}$ konsantrasyonunda artış sağlanmıştır. $\mathrm{Bu}$ artışların kontrole göre Gemlik çeşidinde \%14.4 ve Ayvalık çeşidinde ise \%10.3 oranında gerçekleştiği görülmüştür. Araştırma sonuçlarına B konsantrasyonunun Ayvalık çeşidinde Gemlik çeşidine göre \%8.5 oranında daha yüksek olduğu saptanmıştır. Yapraktan artan dozlarda B uygulamasının diğer besin elementlerinin konsantrasyonları üzerine önemli bir etkide bulunmadığı belirlenmiş̧ir.

Anahtar kelimeler: Bor noksanlığg, B uygulaması, B beslenmesi, yapraktan uygulama, zeytin

\section{The Effect of Foliar Boron Application in Increasing Doses on Laeves Boron Concentration of Two Different Olive (Olea europaea L.) Varieties}

\begin{abstract}
Olive (Olea europaea L.) is a plant sensitive to boron (B) deficiency, and B deficiency, the world and Turkey. In this study, the effect of foliar B applications in increasing doses on different olive varieties was investigated. In the experiment carried out for this purpose, increasing doses of $\mathrm{H}_{3} \mathrm{BO}_{3}(0 \% ; 0.2 \% ; 0.4 \%$; $0.6 \%$ and $0.8 \%)$ were applied to the leaves of Ayvalık and Gemlik olive varieties in two different periods when Som (the period before blooming) and the fruits were the size of chickpea, and the leaf B concentration of the varieties and other nutrients have been determined. According to the results obtained; the B concentration in the leaves of both varieties increased with increasing doses of B application. These increases were observed to be $14.4 \%$ in Gemlik variety and $10.3 \%$ in Ayvalik variety compared to the control. Under all B applications, the B concentration was found to be $8.5 \%$ higher in Ayvalık variety than Gemlik variety. In addition, the effect of foliar application of B in increasing doses on the concentrations of other nutrients in the leaf was statistically insignificant; however, weak correlations were found between some elements.
\end{abstract}

Keywords: Boron deficiency, B application, B nutrition, foliar application, olive

ORCID ID (Yazar sirasına göre)

0000-0001-5353-8224, 0000-0002-8493-5828

\footnotetext{
Yayın Kuruluna Geliş Tarihi: 24.01.2021

Kabul Tarihi: 11.02.2021

${ }^{1}$ Çukurova Üniversitesi, Ziraat Fakültesi, Toprak Bilimi ve Bitki Besleme Bölümü, 01330, Adana, Türkiye.

*E-posta: atorun@cu.edu.tr
} 


\section{Artan Dozlarda Bor Uygulamasının İki Farklı Zeytin (Olea europaea L.) Çeşidinin Yaprak Bor Konsantrasyonu Üzerine etkisi}

\section{Giriș}

Bor (B), sahip olduğu çok yönlü morfolojik ve fizyolojik fonksiyonlarıyla kültür bitkilerinin büyüme ve gelişmesi için mutlak gerekli olan bir mineral besin elementidir (Çakmak ve Römheld, 1997; Goldbach ve Wimmer, 2007; Marschner, 2012; Dridi ve ark., 2018). Dünyanın farklı bölgelerinde bitki yetiştiriciliğinde ortaya çıkan B noksanlığının ülkemizde de önemli bir beslenme problemi olduğu gösterilmiştir. Yapılan survey çalışmalarında; ülkemizde bitkisel üretim altındaki toprakların, en az \%25'inde B noksanlığ $\left(<1 \mathrm{mg} \mathrm{kg}^{-1}\right)$ probleminin olduğu, bazı bölgelerimizde ise (özellikle Orta Anadolu Bölgesinin bazı kısımlarında) B'un, toprakta aşırı (toksik) düzeylerde $\left(>2 \quad \mathrm{mg} \quad \mathrm{kg}^{-1}\right)$ bulunduğu bildirilmiştir (Çakmak, 2016). Toprakların yanı sıra Türkiye'nin farklı hedef bölgelerinde yetiştiriciliği yapılan yaygın birçok bitki türünde farklı $\mathrm{B}$ uygulama metotlarının bitkilerin verim ve kalitesi üzerine etkisi araştırılmıştır (Güneş ve ark., 2016). Elde edilen sonuçlar, B uygulamalarına karşın verim artışı olduğu bildirilmektedir.

Bitki türleri arasında B noksanlığına karşı farklı duyarlılıkların olduğu (Shorrocks, 1997; Torun ve ark., 2018) ve zeytinin B noksanlığına karşı oldukça duyarlı bir bitki olduğu bildirilmektedir (Perica ve ark., 2001). Yaprak veya topraktan B uygulamasinın zeytinde hem verim hem de kalite üzerine iyileştirici etkisi olduğu bilinmektedir. Meyve ağaçlarında yapraktan B uygulamalarının verim üzerine etkisi ilk kez Batjer ve Thompson (1949) tarafindan incelenmiştir. Bu araştırmada armut bitkisine çiçeklenme döneminde yapraktan B uygulamasının meyve tutumunu arttırdığı rapor edilmektedir (Batjer ve Thompson, 1949). Bir diğer çalışmada Hanson (1991) vişne bitkisine yapraktan B uygulamalarının, yaprak B konsantrasyonunda önemli bir farklılığa yol açmadığını ancak tomurcuklarda B konsantrasyonunu \%94 ve çiçeklerde ise $\% 54$ oranında arttırdı ğını saptamıştır. Penca ve ark. (2001) zeytinlerde çiçeklenmeden önce yapraktan B uygulamasının meyve tutumu üzerine etkisini araştırdıkları bir çalışmada yapraktan B uygulamasının zeytinde çiçek ve meyve tutma oranını önemli ölçüde arttırdığını bildirmiştir. Güneş ve ark., (2017)'1, özellikle çiçeklenme ve meyve-tane oluşum döneminde bitkilere yapraktan B uygulamasının yüksek verim ve sürdürebilirlik adına önemli olduğunu bildirmiştir,

Hartmann ve ark., (1966) tarafindan yapılan kapsamlı bahçe denemelerinde zeytinin beslenmesinde $\mathrm{N}$ ve $\mathrm{K}$ ile birlikte B'un önemi de ortaya konmuştur. $\mathrm{Bu}$ araştırmalarda $\mathrm{B}$ uygulamasinın, zeytinde B noksanlık simptomlarını hafiflettiği ve B noksanlığının dünya çapında bir beslenme bozukluğu olduğu kaydedilmiştir.

Bor gübrelemesi ile zeytinde verim artışı sağlandığına ilişkin çok sayıda bildirim bulunmaktadır (Larbi ve ark., 2011; Soyergin, 2010). Ayrıca B beslenmesinin zeytinde çiçek kalitesi ve meyve tutumu (Perica ve ark., 2002) ve $B$ beslenmesi ile verim arasında yakın bir ilişki olduğu da gösterilmiştir (Arrobas ve ark., 2010).

Zeytin bitkisine $\mathrm{K}, \mathrm{P}, \mathrm{Ca}, \mathrm{Mg}$ ve $\mathrm{B}$ uygulamasının, toprak ve bitki analizlerine dayanılarak yapılmasi; ancak, toprak ve bitkideki davranışından dolayı B'un düşük oranlarda da olsa her yıl uygulanmasinın uygun olacağı bildirilmiştir (Rodrigues ve ark., 2012).

FAO verilerine göre, 2017 yılinda dünyada en fazla zeytin ekim alanlarına sahip ülkeler sıralamasinda İspanya, Tunus, İtalya, Fas ve Yunanistan'dan sonra Türkiye 6. sirada yer almıştır. Türkiye'nin toplam ekim alanı içerisindeki payı \%7,83 (FAO, 2019) iken, Uluslararas1 Zeytin Konseyi (IOC) verilerine göre, 2017 y1lında örgüte üye ülkelerde toplam en yüksek zeytinyağ 1 üretim miktarında Türkiye 263.000 ton ile $(\% 9,27)$ dünyada 4 . siradadır (IOC, 2019). Türkiye İstatistik Kurumunun verilerine bakıldığında, Güneydoğu Anadolu Bölgesi içerisinde zeytin üretimi Gaziantep ili, Oğuzeli ilçesinde, toplam 88.768 da alanda, 3301 ton zeytin üretiminin yapıldığ 1 görülmektedir (TÜIKK, 2019).

Zeytin, Akdeniz ve Güneydoğu Anadolu bitki deseni içerisinde giderek arış göstermektedir. $\mathrm{Bu}$ bölgelerde zeytinin $\mathrm{B}$ ile beslenme durumu ve $B$ 'lu gübrelemenin zeytinde B konsantrasyonu, verim ve kalite üzerine etkilerine ilişkin sınırlı sayıda çalışma 


\section{Artan Dozlarda Bor Uygulamasının İki Farklı Zeytin (Olea europaea L.) Çeşidinin Yaprak Bor Konsantrasyonu Üzerine etkisi}

olduğu izlenmektedir. $\mathrm{Bu}$ araştırma Nizip bölgesinde son dönemlerde yetiştiriciliğ yapılan Gemlik ve Ayvalık zeytin çeşitlerinde, yapraktan artan dozlarda B (\%0; \%0,2; \%0,4; $\% 0,6$ ve \%0,8) uygulamasının zeytin bitkisinin yaprak B konsantrasyonu üzerine etkisi araştırılmıştır.

\section{Materyal ve Metot}

Araştırma materyalini, Gaziantep/Oğuzeli ilçesine bağlı Aşağı Güneyse Köyü’nde, üretici koşullarında yetiştiriciliği yapılan 2 farklı zeytin (Olea europaea L. Ayvalık ve Gemlik) bahçesi oluşturmaktadır. Çalışmanın yürütüldügü zeytin bahçesi 40 da alana sahip olup, dikim aralığ 10 x $10 \mathrm{~m}$ şeklindedir ve kuru tarım yapılmaktadır. Çalışma 2014-2015 büyüme sezonunda gerçekleştirilmiştir.

Denemelerin gerçekleştiği bahçelere ilişkin toprak analiz sonuçları Çizelge 1'de verilmiştir. Topraklarda alınabilir B analizi Azomethin-H yöntemi (Bingham, 1982), tekstür Bouyoucous, (1951), alınabilir P Olsen ve ark. (1954), alınabilir K Carson (1980), DTPA'da ekstrakte edilebilir $\mathrm{Zn}, \mathrm{Fe}, \mathrm{Mn}$ ve $\mathrm{Cu}$ elementlerinin analizleri Lindsay ve Norvell (1978)'e göre, kireç Çağlar (1949), organik madde Jackson (1962), pH ve Elektriksel iletkenlik McLean (1982)'e göre yapılmıştır.

Araştırma, tesadüf blokları deneme desenine göre 4 tekrarlamalı ve her tekrarlamada 1 ağaç olacak şekilde yürütülmüştür. Denemeler, 20 adet Gemlik ve 20 adet Ayvalık olmak üzere toplam 40 ağaç ile gerçekleştirilmiştir. Denemelerde yer alan 2 zeytin çeşidi (Gemlik ve Ayvalık) için de bahçelerde habitusları ve yașları (yaklașı 10-12 yaşında) birbirine yakın ağaçlar seçilmiştir (Şekil 1 ve Şekil 2).

Çizelge 1. Çalışma alanı topraklarının fiziksel ve kimyasal özellikleri.

\begin{tabular}{lcc}
\hline Analizler & $0-30 \mathrm{~cm}$ & $30-60 \mathrm{~cm}$ \\
\hline Tekstür Sınıfi & Kil (C) & Kil (C) \\
$\mathrm{EC}\left(\mathrm{mS} \mathrm{cm}^{-1}\right)$ & 0,10 & 0,20 \\
$\mathrm{pH}$ & 8,20 & 8,10 \\
$\mathrm{CaCO}_{3}(\%)$ & 13,8 & 13,3 \\
Org.Madde (\%) & 1,60 & 1,20 \\
$\mathrm{~B}\left(\mathrm{mg} \mathrm{kg}^{-1}\right)$ & 0,47 & 0,32 \\
$\mathrm{Cu}\left(\mathrm{mg} \mathrm{kg}^{-1}\right)$ & 1,84 & 1,82 \\
$\mathrm{Mn}\left(\mathrm{mg} \mathrm{kg}^{-1}\right)$ & 6,86 & 5,99 \\
$\mathrm{Fe}\left(\mathrm{mg} \mathrm{kg}^{-1}\right)$ & 5,71 & 6,36 \\
$\mathrm{Zn}\left(\mathrm{mg} \mathrm{kg}^{-1}\right)$ & 0,20 & 0,70 \\
$\mathrm{~K}\left(\mathrm{mg} \mathrm{kg}^{-1}\right)$ & 402 & 323 \\
$\mathrm{P}\left(\mathrm{mg} \mathrm{kg}^{-1}\right)$ & 8,57 & 4,78 \\
\hline
\end{tabular}

Çizelge 2. Yapraktan B uygulama zamanı ve uygulama dozu.

\begin{tabular}{cccc}
\hline Ağaç & Uygulama & Uygulama zamanı & Uygulama Miktarı \\
\hline \multirow{2}{*}{ Zeytin } & 1 & Som (çiçek açmadan önceki dönem) döneminde & Toplam Miktarın Yarısı \\
& 2 & Meyveler nohut büyüklüğü döneminde & Toplam miktarın Yarısı \\
\hline
\end{tabular}




\section{Artan Dozlarda Bor Uygulamasının İki Farklı Zeytin (Olea europaea L.) Çeşidinin Yaprak Bor Konsantrasyonu Üzerine etkisi}

Çizelge 3. Zeytinde yaprak sınır değerleri (Kacar ve İnal, 2010)

\begin{tabular}{lccc}
\hline \multicolumn{1}{c}{ Element } & Noksan & Yeterli & Fazla \\
\hline $\mathrm{N}(\%)$ & $<1.5$ & $1.5-2.5$ & $>2.5$ \\
$\mathrm{P}\left(\mathrm{mg} \mathrm{kg}^{-1}\right)^{*}$ & $<1000$ & $1000-3000$ & $>3000$ \\
$\mathrm{~K}(\%)$ & $0.5-0.8$ & $0.9-1.2$ & $>1.2$ \\
$\mathrm{Mn}\left(\mathrm{mg} \mathrm{kg}^{-1}\right)$ & $<25$ & $>25$ & \\
$\mathbf{B}\left(\mathrm{mg} \mathrm{kg}^{-1}\right)$ & $\mathbf{1 5 - 1 9}$ & $\mathbf{2 0 -} \mathbf{7 5}$ & $>\mathbf{7 5}$ \\
$\mathrm{Zn}\left(\mathrm{mg} \mathrm{kg}^{-1}\right)$ & $<25$ & $>25$ & \\
\hline
\end{tabular}

*P \% biriminden $\mathrm{mg} \mathrm{kg}^{-1}$ transforme edilmiştir.

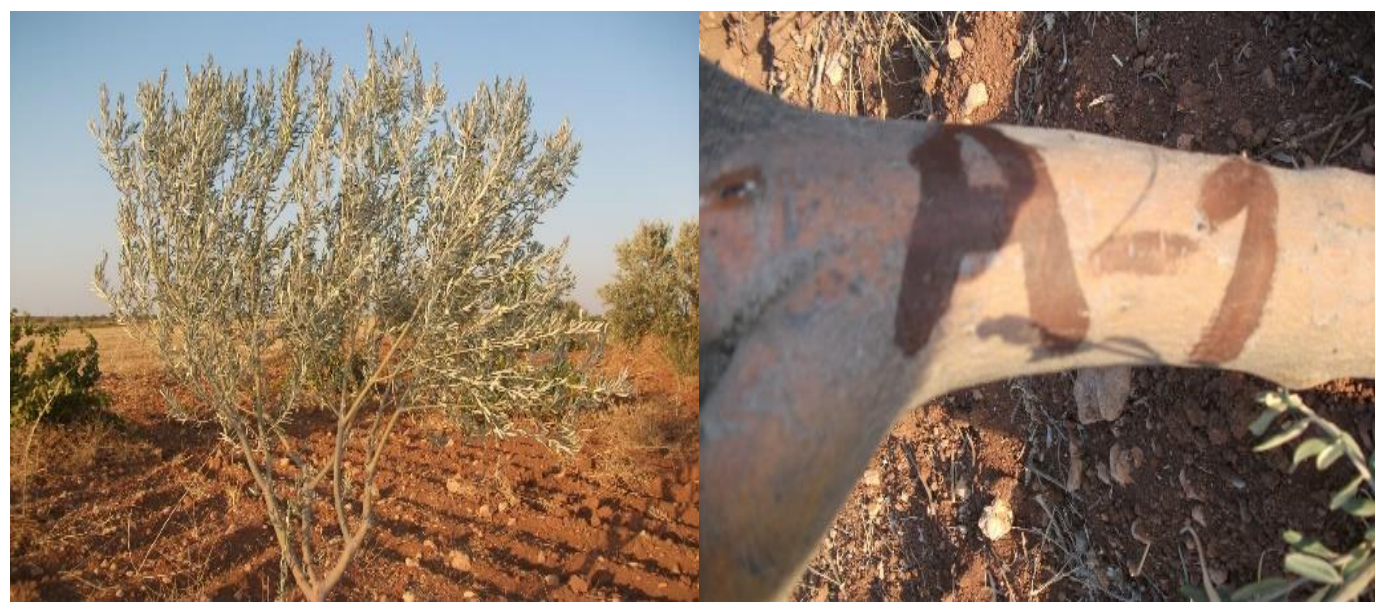

Şekil 1. Denemede yapraktan Bor uygulaması yapılan Ayvalık çeşidine ait Zeytin ağaçlarından görünüm

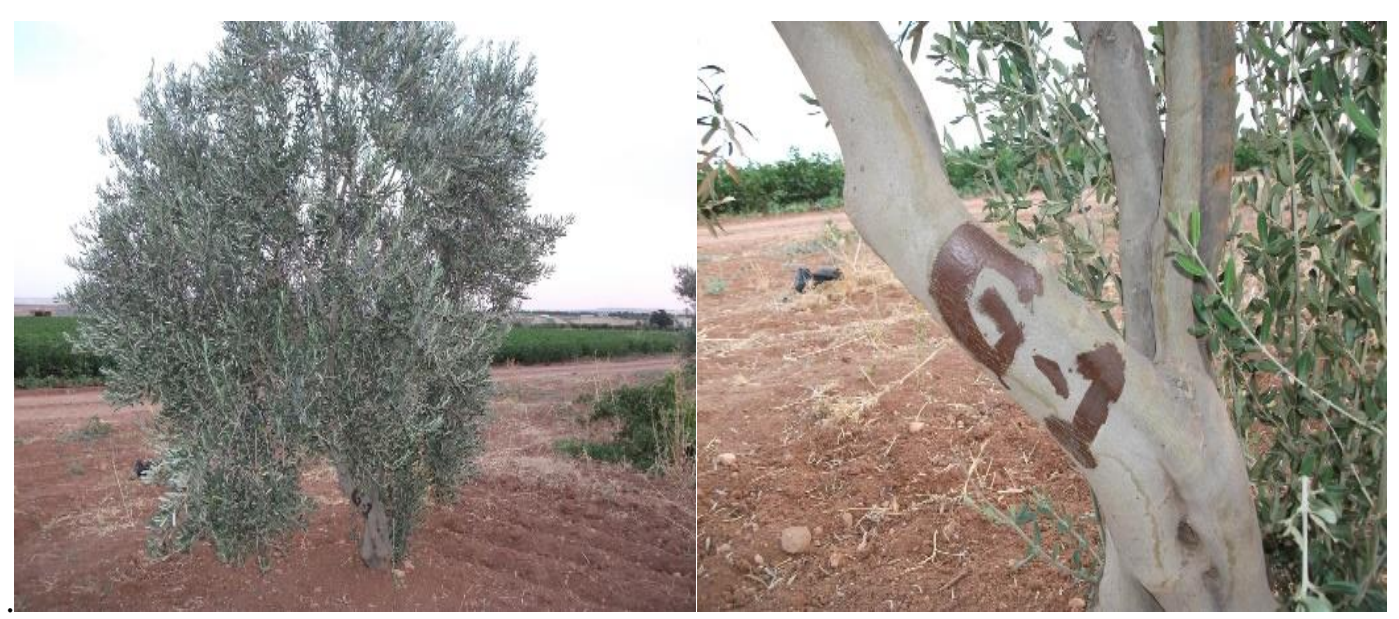

Şekil 2. Denemede yapraktan Bor uygulaması yapılan Gemlik çeşidine ait Zeytin ağaçlarından görünüm. 


\section{Artan Dozlarda Bor Uygulamasının İki Farklı Zeytin (Olea europaea L.) Çeşidinin Yaprak Bor Konsantrasyonu Üzerine etkisi}

Gübreleme: Taban gübresi olarak; Ocak ay1 sonunda ağaç taç iz düşümüne gelecek șekilde $20-30 \mathrm{~cm}$ derinlikte ve $25-30 \mathrm{~cm}$ genişliğinde açılan banda $1.5 \mathrm{~kg}$ ağaç ${ }^{-1}$ TSP (Triple süper fosfat \% 42-44) ve $60 \mathrm{~kg}_{\text {ağaç }}^{-1}$ yanmış çiftlik gübresi uygulanmıştır. Şubat ayı sonunda (ilkbahar yağışlarından önce) ağaç taç iz düşümüne $3.0 \mathrm{~kg}$ ağaç-1 amonyum sülfat gübresi $(\% 21 \quad \mathrm{~N})$ serpilerek uygulama yapılmıştır.

Bor Uygulamaları: Araştırmada 0-10-20-30$40 \mathrm{~g} \quad \mathrm{H}_{3} \mathrm{BO}_{3}$ ağaç$^{-1}$ dozunda 5 farklı $\mathrm{B}$ uygulaması yapılmıştır. $\mathrm{Bu}$ çerçevede ilgili dozlar 5 litre suda eritilmiş ve bu şekilde \% 00.2-0.4-0.6 ve $0.8 \quad \mathrm{H}_{3} \mathrm{BO}_{3} \quad$ çözeltileri hazırlanmıștır. $\mathrm{Bu}$ çözeltilerin yarısı zeytin için kritik büyüme dönemleri olan som (çiçek açmadan önceki dönem) dönemi ve kalan yarısı ise meyveler nohut büyüklügüne geldiği dönem olmak üzere 2 farklı büyüme döneminde (Çizelge 2) sırt pülverizatörü ile uygulanmıştır.

Yaprak Örneklemesi: Çalışmada yaprak örneklemesi, uygulamalar yapıldıktan sonra zeytin bitkisi için en uygun yaprak alma dönemi olarak belirtilen Aralık ay1 sonunda (Eryüce, 1979; Püskülcü, 1981; Soyergin, 2010) yıllık uç sürgünlerin ortasındaki karşılıklı yaprak çifti şeklinde ve ağaçların dört bir tarafından alınarak gerçekleştirilmiştir. Alınan yaprak örnekleri laboratuvar ortamına getirilerek seyreltik asitli $(\% 0.1 \mathrm{HCl})$ sudan geçirilmiş ve saf su ile iki kere yıkanarak, en az 48 saat süresince etüvde $70^{\circ} \mathrm{C}$ 'de kurutulmuştur. Ardından agat değirmende öğütülerek analize hazır hale getirilmiştir.

Analizler: Örnekler kuru yakma (Kacar ve İnal, 2010) metoduna göre yakılarak analize hazırlanmıştır. Elde edilen süzüklerde B analizleri Azomethin-H yöntemine (Bingham, 1982) göre spektrofotometrik olarak yapılmıştır. Fosfor tayini, spektrofotometrik (Barton,1948), K, Fe, Zn ve Mn ölçümleri ise Atomik Absorpsiyon Spektrofotometre (Varian FS 220) ile yapılmıştır. Azot, Kjeldahl yöntemine (Bremner 1965) göre belirlenmiştir.

Araştırma sonucu elde edilen verilere varyans analizi uygulanmış ve sonuçlara ait ortalamalar ise XLSTAT programı ile en küçük anlamlı fark testi (LSD) uygulanmıştır. Analizlerde önem seviyesi \%5 olarak alınmıştır.

\section{Bulgular ve Tartışma}

Artan dozlarda yapraktan B uygulamasinın zeytin bitkisinin yaprak B konsantrasyonuna etkisini belirlemek amaciyla 2 farklı zeytin çeşidine (Olea europaea L. Gemlik ve Ayvalık) 2 farklı büyüme döneminde yapraktan artan dozlarda $\mathrm{H}_{3} \mathrm{BO}_{3}$ $(\% 0 ; \% 0,2 ; \% 0,4 ; \% 0,6$ ve $\% 0,8)$ uygulamas1 yapılmış ve uygulama dozuna göre yapraktaki $\mathrm{B}$ ve diğer besin elementleri konsantrasyonları belirlenmiştir.

Yapraktan B uygulamasının Gemlik ve Ayvalık çeşitlerinin ortalama yaprak B konsantrasyonunda artışlara neden olduğu görülmüş ancak yalnızca $\% 0.8 \mathrm{~B}$ uygulaması ile istatistiksel olarak önemli düzeyde artış saptanmıştır (Çizelge 4). Çeşitlere bakılmaksızın artan dozlarda B uygulamasına göre değerlendirildiğinde, en yüksek $\mathrm{B}$ konsantrasyonu $92.8 \mathrm{mg} \mathrm{kg}^{-1}$ olarak \%0.8 uygulamasında ölçülmüş (Çizelge 4) ve uygulamadan kaynaklanan artışın kontrole göre \%18.8 olduğu görülmüştür.

Artan dozlarda B uygulaması ile Ayvalık zeytin çeşidinin B konsantrasyonu Gemlik çeşidinden daha yüksek olmuş, ancak istatistiksel olarak önemli bir fark belirlenmemiştir ( $>0.05)$. Gemlik çeşidinin ortalama B konsantrasyonu $82.2 \mathrm{mg} \mathrm{kg}^{-1}$ iken, en yüksek $98.8 \mathrm{mg} \mathrm{kg}^{-1}(\% 0.8 \mathrm{~B})$ ve en düşük ise $73.7 \mathrm{mg} \mathrm{kg}^{-1}$ (kontrol) olarak belirlenmiş ve B uygulamasindan kaynaklanan konsantrasyon artış1 \%34.1 şeklinde olmuştur. Aynı değerler Ayvalık zeytin çeşidinde ise ortalama $89.2 \mathrm{mg}$ $\mathrm{kg}^{-1}$, en yüksek $94.5 \mathrm{mg} \mathrm{kg}^{-1}$ (\%0.6 B) ve en düşük ise $82.4 \mathrm{mg} \mathrm{kg}^{-1}$ (kontrol) olarak ölçülmüş ve $\mathrm{B}$ uygulamasından kaynaklanan konsantrasyon artış1 \%14.7 şeklinde hesaplanmıştır. Kontrole göre artan dozlarda B uygulaması ile Gemlik çeşidinin B konsantrasyon artışı surasıyla \% $4.5, \% 7.5$, $\% 19.9$ ve $\% 34.1$ düzeyinde, Ayvalık çeşidinde ise $\% 7.8, \% 13.5, \% 14.7$ ve $\% 5.2$ düzeylerinde olmuştur (Çizelge 4). Yapraktan artan dozlarda $\mathrm{B}$ gübrelemesi ile zeytin çeşitlerinin yaprak B konsantrasyonlarında artış meydana gelmiştir. 


\section{Artan Dozlarda Bor Uygulamasının İki Farklı Zeytin (Olea europaea L.) Çeşidinin Yaprak Bor Konsantrasyonu Üzerine etkisi}

$\mathrm{Bu}$ durum, temelde deneme alanı toprağının $\mathrm{B}$ konsantrasyonunun noksan ve yeter seviyesinin alt sınırına yakın (Çizelge 1) olmasıyla ilișkili olduğu düşünülmüştür (Gündeşli ve Nikpeyma, 2016).

Wolf (1971)'un toprakta alınabilir B için belirttiği kritik sınır değerine göre, çalışmada yer alan zeytin bahçelerinin iki farklı derinliğinden alınan toprak örneklerinin alınabilir B konsantrasyon değerlerinin (0.47$0.32 \mathrm{mg} \mathrm{kg}^{-1}$ ) yetersiz olduğu görülmüştür.

Artan dozlarda B uygulamasinın 2 zeytin çeşidinde (Gemlik ve Ayvalık) yaprak makro

(N, P, K) ve mikro ( $\mathrm{Zn}, \mathrm{Fe}, \mathrm{Mn}$ ) besin elementleri konsantrasyonları üzerine etkisi Çizelge 5'de verilmiştir.

Gemlik ve Ayvalık zeytin çeşitlerinin yaprak N konsantrasyonu Gemlik çeşidinde $\% 1.92$ olup, en yüksek \%2.01 ve en düşük ortalama N konsantrasyonu \%1.85'tir. Ayval1k çeşidinde ise ortalama \%1.82, en yüksek \%1.91 ve en düşük \%1.70 olarak ölçülmüştür (Çizelge 6). $\mathrm{Bu}$ değerlerin Kacar ve İnal (2010) tarafından zeytin bitkisi için önerilen N sınır değerinden (\%1.5) yüksek olduğu belirlenmiştir (Çizelge 3).

Yapraktan B uygulama dozlarına göre, yaprak N konsantrasyonları incelendiğinde, en yüksek $\mathrm{N}$ konsantrasyonun \%1.92 ile \%0.6 uygulamasında, en düşük $\mathrm{N}$ konsantrasyonu ise $\% 1.83$ ile kontrol uygulamasında ölçüldüğü izlenmektedir (Çizelge 5). Bu sonuçlara göre yapraktan B uygulama dozlarının Zeytinde yaprak $\mathrm{N}$ içeriğine önemli bir etkisinin olmadığı görülmektedir. Antep fistığ 1 ile yapılan benzer bir çalışmada da artan dozlarda $\mathrm{B}$ uygulamasının yaprak $\mathrm{N}$ konsantrasyonunda önemli bir farklılık yaratmadı $\breve{g} 1, \quad N$ ve $B$ interaksiyonunun önemli olmadığı saptanmıştır (Torun ve ark., 2021). Dursun (2010) tarafindan yürütülen benzer bir çalışmada da Ayvalık zeytin çeşidine $\mathrm{B}$ gübre uygulamasının bitkinin $\mathrm{N}$ konsantrasyonunu önemli düzeyde etkilemediği rapor edilmektedir.

Artan dozlarda B uygulamasının, yaprak K konsantrasyonuna hem çeşit (Gemlik ve Ayvalık) hem de uygulama dozları bazında ( $>0.05)$ önemli bir etkide bulunmadığ saptanmıştır (Çizelge 5). Yaprak K değerlerinin ortalamaları dikkate alınarak değerlendirildiğinde, Gemlik çeşidinde yaprak $\mathrm{K}$ konsantrasyonu ortalama $\% 0.40$, en yüksek $\mathrm{K}$ konsantrasyonunun $\% 0.42$ ve en düşük $\mathrm{K}$ konsantrasyonunun ise \%0.30, Ayvalık çeşidinin ise ortalama $\mathrm{K}$ konsantrasyonunun $\% 0.48$, en yüksek K konsantrasyonunun $\% 0.54$ ve en düşük $\mathrm{K}$ konsantrasyonunun ise $\% 0.41$ olduğu izlenmektedir. (Çizelge 5). Elde edilen bu değerler Kacar ve İnal (2010) tarafından Zeytin bitkisi için önerilen $\mathrm{K}$ noksanlık değerleri (\%0.5-0.8) ile karşılaştırıldığında, K açısından düşük olduğu görülmektedir (Çizelge 3). Yapılan çeşitli araştırmalarda da B gübrelemesinin $\mathrm{K}$ konsantrasyonu üzerine etkileri genellikle önemli olmadığ bildirilmektedir (Razmjoo, 1997; Aydın, 2005; Torun ve ark., 2021).

Zeytin çeşitleri ve gübre dozlarına göre yaprak P konsantrasyon ortalamaları bazında değerlendirildiğinde, farkın istatistiksel olarak önemli olmadığ $\quad(\mathrm{p}>0.05) \quad$ görülmektedir (Çizelge 5). Yapraktan artan dozlarda B uygulamasının iki farklı zeytin çeşidinin (Gemlik ve Ayvalı) yaprak P konsantrasyonlarına etkisi incelendiğinde; Gemlik çeşidinin ortalama $P$ konsantrasyonunun $604.54 \mathrm{mg} \mathrm{kg}^{-1}$, en yüksek $\mathrm{P}$ konsantrasyonunun $647.24 \mathrm{mg} \mathrm{kg}^{-1}$ ve en düşük ise $544.54 \mathrm{mg} \mathrm{kg}^{-1}$ olduğu, Bu sonuçların Ayvalık çeşidinde ise ortalama, en yüksek ve en düşük yaprak $\mathrm{K}$ konsantrasyonu için sıra ile $662.46 \mathrm{mg} \mathrm{kg}^{-1}, ; 715.01 \mathrm{mg} \mathrm{kg}^{-1}$ ve $622.51 \mathrm{mg}$ $\mathrm{kg}^{-1}$ olduğu görülmüştür (Çizelge 5). Bu değerlerin Kacar ve İnal (1999) tarafindan verilen zeytin bitkisi için $\mathrm{P}$ konsantrasyonu yeterlilik alt sınır değerinden $\left(1000 \mathrm{mg} \mathrm{kg}^{-1}\right)$ oldukça düşük olduğu, bu durumun deneme alanı toprağının hem yarayışlı $\mathrm{P}$ açısından düşük hem de çok fazla kireçli olmasından kaynaklanabileceğine yorumlanmıştır (Çizelge 1). Sonuçlar yapraktan B uygulama dozlarına göre değerlendirildiğinde, $\mathrm{P}$ açısından en yüksek ortalama değerin $652.62 \mathrm{mg} \mathrm{kg}^{-1}$ ile $\% 0.4$ B uygulamasında ölçülürken, en düşük ortalama değerin ise $583.52 \mathrm{mg} \mathrm{kg} \mathrm{kg}^{-1}$ ile $\% 0.8^{\prime}$ lik uygulamaya ait olduğu görülmüştür (Çizelge 5). Yapraktan artan dozlarda B uygulamasının zeytin çeşitlerinin yaprak $\mathrm{Zn}$ konsantrasyonu üzerine etkisi 


\section{Artan Dozlarda Bor Uygulamasının İki Farklı Zeytin (Olea europaea L.) Çeşidinin Yaprak Bor Konsantrasyonu Üzerine etkisi}

değerlendirildiğinde, Gemlik çeşidinin ortalama $\mathrm{Zn}$ konsantrasyonunun $12.58 \mathrm{mg} \mathrm{\textrm {kg } ^ { - 1 }}$, en yüksek $22.86 \mathrm{mg} \mathrm{kg}^{-1}$, en düşük $\mathrm{Zn}$ konsantrasyonunun ise $8.48 \mathrm{mg} \mathrm{kg}^{-1}$ olduğu, Ayvalık çeşidinde ise ortalama $\mathrm{Zn}$ konsantrasyonunun $10.11 \mathrm{mg} \mathrm{kg}^{-1}$, en yüksek $14.81 \mathrm{mg} \mathrm{kg}^{-1}$ ve en düşük $7.53 \mathrm{mg} \mathrm{kg}^{-1}$ olduğu ortaya çıkmıştır (Çizelge 5).

$\mathrm{Bu}$ değerler Kacar ve İnal (2010) tarafindan zeytin bitkisi için verilen $\mathrm{Zn}$ sınır değerinden (25 mg kg-1) "düşük" olduğu belirlenmiştir (Çizelge 3). Sonuçlar gübre dozlarına göre değerlendirildiğinde, en yüksek ortalama $\mathrm{Zn}$ konsantrasyonu $15.85 \mathrm{mg} \mathrm{kg}^{-1}$ ile B'un $\% 0.2$ uygulamasında, en düşük ortalama değer ise $8.77 \mathrm{mg} \mathrm{kg}^{-1}$ ile B’un \%0.6 uygulamasında ölçülmüştür. Hem bitki çeşitleri hem de gübre dozlarına göre ortalamalar arasındaki farkın istatistiksel $(\mathrm{p}>0.05)$ olarak önemli olmadığ tespit edilmiştir (Çizelge 5).

Zeytin çeşitlerinin yaprak Fe konsantrasyonu ortalamaları değerlendirildiğinde, Gemlik çeşidinin ortalama Fe konsantrasyonu 177.05 $\mathrm{mg} \mathrm{kg}{ }^{-1}$, en yüksek Fe konsantrasyonu 232.61 $\mathrm{mg} \mathrm{kg}^{-1}$ ve en düşük ise $133.49 \mathrm{mg} \mathrm{kg-1}$, Ayvalık çeşidinin ortalama yaprak Fe konsantrasyonu $183.76 \mathrm{mg} \mathrm{kg}^{-1}$, en yüksek Fe konsantrasyonu $207.04 \mathrm{mg} \mathrm{kg}^{-1}$ ve en düşük Fe konsantrasyonu ise $171.33 \mathrm{mg} \mathrm{kg}^{-1}$ olduğu ortaya çıkmıştır (Çizelge 5). Gübre dozlarına göre değerlendirildiğinde en yüksek ortalama Fe konsantrasyonu $201.97 \mathrm{mg} \mathrm{kg}^{-1}$ olarak kontrol (\%0 B) uygulamasında ölçülürken, en düşük Fe konsantrasyonu ise $160.38 \mathrm{mg} \mathrm{kg}^{-1}$ ile B'un \%0.4 uygulamasında ölçülmüştür (Çizelge 5). Hem çeşitler hem de gübre dozlarına göre ortalamalar arasındaki farkın istatistiksel ( $>0.05)$ olarak önemli olmadiğ 1 tespit edilmiştir (Çizelge 5).
Artan dozlarda yapraktan B uygulamaları ile 2 Zeytin çeşidinin yaprak Mn konsantrasyonu değerlendirildiğinde, Gemlik çeşidinin ortalama Mn konsantrasyonu $76.19 \mathrm{mg} \mathrm{kg}{ }^{-1}$, en yüksek değerin $87.17 \mathrm{mg} \mathrm{kg}^{-1}$ ve en düşük değerin ise $67.38 \mathrm{mg} \mathrm{kg}{ }^{-1}$ olduğu, Ayvalık çeşidinde ortalama Mn konsantrasyonu $63.90 \mathrm{mg} \mathrm{kg}^{-1}$, en yüksek değerin $69.11 \mathrm{mg} \mathrm{kg}^{-1}$ ve en düşük değerin ise $59.77 \mathrm{mg} \mathrm{kg}^{-1}$ olduğu ortaya çıkmıştır (Çizelge 5). Bu değerler Kacar ve İnal (2010) tarafindan zeytin bitkisi için verilen $\mathrm{Mn}$ konsantrasyonu sınır değerinden $\left(25 \mathrm{mg} \mathrm{kg}^{-1}\right.$ ) yüksek olduğu görülmüştür (Çizelge 3). Artan dozlarda B uygulamasının Zeytin çeşitlerinin yaprak Mn konsantrasyonuna etkisinin istatistiksel olarak önemli olduğu tespit edilmiştir ( $p>0.05)$. Uygulama dozlarına göre en yüksek ortalama Mn değeri $78.14 \mathrm{mg} \mathrm{kg}^{-1}$ ile B'un \%0.6 uygulamasında ve en düşük ortalama değerin ise $63.58 \mathrm{mg} \mathrm{kg}^{-1}$ ile B'un $\% 0.8$ uygulamasında ölçülmüştür (Çizelge 5).

Artan dozlarda B uygulamasinın zeytin çeşitlerinin yaprak B konsantrasyonu ile diğer besin elementleri arasındaki ilişkiler de incelenmiştir (Çizelge 6). Zeytin çeşitleri yaprak B konsantrasyonu ile diğer besin elementleri arasında önemli bir ilişki olmadı̆̆ saptanmıştır. Diğer besin elementleri arasındaki ilişkiler incelendiğinde $\mathrm{N}-\mathrm{Fe}(\mathrm{r}=0.35 ; \mathrm{p}<0.05)$ arasında negatif; Fe ile $\mathrm{Zn} \quad(\mathrm{r}=0.31 ; \mathrm{p}<0.05)$ arasında pozitif; K-Mn arasinda $(\mathrm{r}=0.32$; $\mathrm{p}<0.05)$ negatif ve Mn ile $\mathrm{Zn}(\mathrm{r}=0.32$; $\mathrm{p}<0.05)$ arasında pozitif zayıf ilişkiler saptanmıştır. Gökdemir (2016) B uygulamasının bağda, yaprakların besin element konsantrasyonunu etkilediğini; uygulama ile $\mathrm{N}, \mathrm{P}, \mathrm{Ca}, \mathrm{Mg}, \mathrm{Zn}, \mathrm{Cu}$ ve Mn konsantrasyonunda artış, buna karşın Fe ve $\mathrm{K}$ konsantrasyonunda azalış olduğunu bildirmektedir.

Çizelge 4. Yapraktan artan dozlarda $\mathrm{H}_{3} \mathrm{BO}_{3}$ uygulamasının Gemlik ve Ayvalık zeytin çeşitlerinde yaprak B konsantrasyonuna $\left(\mathrm{mg} \mathrm{kg}^{-1}\right)$ etkisi

\begin{tabular}{lcccccc}
\hline Çeşit & Kontrol & \%0.2 & \%0.4 & \%0.6 & \%0.8 & ort. \\
\hline Gemlik & 73.7 & 77.0 & 79.2 & 82.2 & 98.8 & $82.2 \mathrm{a}$ \\
Ayvalık & 82.4 & 88.8 & 93.5 & 94.5 & 86.7 & $89.2 \mathrm{a}$ \\
\hline Ortalama & $78.1 \mathrm{~b}$ & $82.9 \mathrm{~b}$ & $86.4 \mathrm{ab}$ & $88.4 \mathrm{ab}$ & $92.8 \mathrm{a}$ & \\
\hline
\end{tabular}




\section{Artan Dozlarda Bor Uygulamasının İki Farklı Zeytin (Olea europaea L.) Çeşidinin Yaprak Bor Konsantrasyonu Üzerine etkisi}

Çizelge 5. Yapraktan artan dozlarda $\mathrm{H}_{3} \mathrm{BO}_{3}$ uygulamasının Gemlik ve Ayvalık zeytin çeşitlerinde yaprak N, P, K, Zn, Fe ve Mn konsantrasyonuna üzerine

\begin{tabular}{|c|c|c|c|c|c|c|}
\hline & $\mathbf{N}$ & $\mathbf{P}$ & $\mathbf{K}$ & Zn & $\mathbf{F e}$ & Mn \\
\hline & $(\%)$ & $\left(\mathrm{mg} \mathrm{kg}^{-1}\right)$ & $(\%)$ & $\left(\mathrm{mg} \mathrm{kg}^{-1}\right)$ & $\left(\mathrm{mg} \mathrm{kg}^{-1}\right)$ & $\left(\mathrm{mg} \mathrm{kg}^{-1}\right)$ \\
\hline \multicolumn{7}{|l|}{ Gemlik } \\
\hline Kontrol & 1.90 & 626.84 & 0.41 & 9.86 & 158.50 & 72.46 \\
\hline$\% 0.2$ & 1.85 & 647.24 & 0.40 & 22.86 & 232.61 & 81.51 \\
\hline$\% 0.4$ & 2.01 & 590.23 & 0.41 & 11.68 & 133.49 & 72.38 \\
\hline$\% 0.6$ & 1.92 & 613.86 & 0.30 & 10.00 & 171.04 & 87.17 \\
\hline$\% 0.8$ & 1.90 & 544.53 & 0.42 & 8.48 & 189.61 & 67.38 \\
\hline \multicolumn{7}{|l|}{ Ayvalık } \\
\hline Kontrol & 1.75 & 643.45 & 0.48 & 14.81 & 174.75 & 60.98 \\
\hline$\% 0.2$ & 1.86 & 651.55 & 0.41 & 8.84 & 171.33 & 62.57 \\
\hline$\% 0.4$ & 1.70 & 715.01 & 0.49 & 9.36 & 187.26 & 67.06 \\
\hline$\% 0.6$ & 1.91 & 679.79 & 0.48 & 7.53 & 178.40 & 69.11 \\
\hline \multirow[t]{2}{*}{$\% 0.8$} & 1.88 & 622.51 & 0.54 & 9.99 & 207.04 & 59.77 \\
\hline & \multicolumn{6}{|c|}{ Ortalamalar } \\
\hline Gemlik & $1.92 \mathrm{a}$ & $604.54 \mathrm{a}$ & $0.40 \mathrm{a}$ & $12.58 \mathrm{a}$ & $177.05 \mathrm{a}$ & 76.19a \\
\hline Ayvalık & $1.82 \mathrm{a}$ & $662.46 \mathrm{a}$ & $0.48 \mathrm{a}$ & $10.11 \mathrm{a}$ & $183.76 \mathrm{a}$ & $63.90 \mathrm{~b}$ \\
\hline Kontrol & $1.83 \mathrm{a}$ & $635.15 \mathrm{a}$ & $0.45 \mathrm{a}$ & $12.34 \mathrm{a}$ & $166.63 \mathrm{a}$ & $66.72 \mathrm{ab}$ \\
\hline$\% 0.2$ & $1.86 \mathrm{a}$ & $649.40 \mathrm{a}$ & $0.41 \mathrm{a}$ & $15.85 \mathrm{a}$ & $201.97 \mathrm{a}$ & $72.04 b$ \\
\hline$\% 0.4$ & $1.86 \mathrm{a}$ & $652.62 \mathrm{a}$ & $0.45 \mathrm{a}$ & $10.52 \mathrm{a}$ & $160.38 \mathrm{a}$ & 69.72ab \\
\hline$\% 0.6$ & $1.92 \mathrm{a}$ & $646.83 a$ & $0.39 \mathrm{a}$ & $8.77 \mathrm{a}$ & $174.72 \mathrm{a}$ & $78.14 \mathrm{a}$ \\
\hline$\% 0.8$ & $1.89 \mathrm{a}$ & $583.52 \mathrm{a}$ & $0.48 \mathrm{a}$ & $9.24 \mathrm{a}$ & $198.33 \mathrm{a}$ & $63.58 \mathrm{ab}$ \\
\hline
\end{tabular}

Çizelge 6. Yapraktan artan dozlarda $\mathrm{H}_{3} \mathrm{BO}_{3}(\% 0 ; \% 0.2 ; \% 0.4 ; \% 0.6$ ve \%0.8) uygulamasının Zeytin çeşitlerinin yaprağındaki besin elementleri arasındaki korelasyon analiz sonuçları

\begin{tabular}{|c|c|c|c|c|c|c|c|c|}
\hline 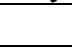 & & Doz & B & $\mathbf{P}$ & $\mathbf{K}$ & $\mathbf{N}$ & Mn & $\mathbf{F e}$ \\
\hline \multirow{2}{*}{ B } & $\mathrm{r}$ & -0.17 & & & & & & \\
\hline & $\mathrm{p}$ & 0.31 & & & & & & \\
\hline \multirow{2}{*}{$\mathbf{P}$} & $\mathrm{r}$ & -0.19 & -0.08 & & & & & \\
\hline & $\mathrm{p}$ & 0.23 & 0.63 & & & & & \\
\hline \multirow{2}{*}{$\mathbf{K}$} & $\mathrm{r}$ & 0.14 & -0.23 & 0.19 & & & & \\
\hline & $p$ & 0.39 & 0.16 & 0.25 & & & & \\
\hline \multirow{2}{*}{$\mathbf{N}$} & $\mathrm{r}$ & 0.17 & -0.21 & -0.19 & -0.10 & & & \\
\hline & $p$ & 0.29 & 0.19 & 0.25 & 0.55 & & & \\
\hline \multirow{2}{*}{ Mn } & $\mathrm{r}$ & 0.00 & -0.07 & 0.29 & $-0.32 *$ & 0.08 & & \\
\hline & $\mathrm{p}$ & 0.99 & 0.68 & 0.07 & 0.04 & 0.64 & & \\
\hline \multirow{2}{*}{$\mathbf{F e}$} & $\mathrm{r}$ & 0.12 & 0.04 & 0.26 & -0.04 & $-0.35^{*}$ & 0.24 & \\
\hline & $\mathrm{p}$ & 0.48 & 0.81 & 0.11 & 0.81 & 0.03 & 0.13 & \\
\hline \multirow{2}{*}{ Zn } & $\mathrm{r}$ & -0.22 & 0.04 & 0.19 & -0.17 & 0.14 & 0.32* & $0.31^{*}$ \\
\hline & $p$ & 0.16 & 0.81 & 0.24 & 0.29 & 0.39 & 0.04 & 0.04 \\
\hline
\end{tabular}




\section{Artan Dozlarda Bor Uygulamasının İki Farklı Zeytin (Olea europaea L.) Çeşidinin Yaprak Bor Konsantrasyonu Üzerine etkisi}

\section{Sonuç ve Öneriler}

$\mathrm{Bu}$ çalışma zeytin bitkisine yapraktan artan dozlarda $\mathrm{H}_{3} \mathrm{BO}_{3}$ (kontrol, \%0.2; \%0.4; \%0.6 ve $\% 0.8$ ) uygulamasinin yaprak B konsantrasyonuna etkilerinin incelenmesi amacı ile gerçekleştirilmiştir. Bu amaca yönelik olarak bitki çeşitleri ve uygulama dozlarına göre yaprak B konsantrasyonu belirlenmiş ve aralarındaki farklılığın istatistiksel olarak önemli olup olamdığı analiz edilmiştir. Analiz sonucunda, bitki çeşitleri ve uygulanan gübre dozlarına göre B konsantrasyonundaki değişimin istatistiksel olarak önemli olduğu ancak bitki $\mathrm{x}$ gübre interaksiyonuna göre $\mathrm{B}$ konsantrasyonundaki değişimin istatistiksel olarak önemli olup olmadığı tespit edilmiştir. Ayrıca, bazı gübre dozlarına göre bitkilerdeki B konsantrasyonu ortalamaları arasinda istatistiksel olarak önemli farkl1l1klar tespit edilmiştir. Ancak kontrol ile $\mathrm{H}_{3} \mathrm{BO}_{3}$ ' in \%0.4'lük ve $\% 0.2^{\prime}$ lik ile $\% 0.8^{\prime}$ lik doz uygulamaları arasındaki farkların istatistiksel olarak önemli olmadığı belirlenmiştir. Gemlik ve Ayvalık zeytin çeşitlerinin yaprak $\mathrm{P}$ ve $\mathrm{N}$ konsantrasyonlarının bitki çeşitlerine göre istatistiksel olarak önemli farkl1lıklar gösterdiği belirlenmiştir.

Araştırmanın amaçlarından biri de yapraktan artan dozlarda B uygulamasinın zeytin bitkisinin diğer besin elementi konsantrasyonunu nasıl etkilediğinin belirlenmesidir. Artan dozlarda B uygulamasının zeytin bitkisi yaprağında bulunan elementlerin konsantrasyonları üzerinde istatistiksel olarak önemli sayılabilecek bir etkisinin olmadığı tespit edilmiştir. Bunun yanında araştırmada kullanılan Gemlik ve Ayvalık zeytin çeşitlerinin yaprak $\mathrm{P}$ ve $\mathrm{N}$ konsantrasyonlarının bitki çeşitlerine göre istatistiksel olarak önemli farklılıklar gösterdiği belirlenmiştir. Yapraktan B uygulaması ile 2 zeytin çeşidinin yaprak B konsantrasyonu ile diğer besin elementleri arasında Mn dışında önemli bir ilişki olmadığı saptanmıştır.

Araştirma sonuçları Güneydoğu Anadolu bölgesi (Oğuzeli/Antep) zeytin plantasyonlarında, toprakta alınabilir B içeriğinin yeterli olmadığı ve bununla ilintili olarak B açısından yeterli düzeyde beslenmemiş $\begin{array}{llll}\text { alanlarda yapraktan } \% & 0.4 & \text { 'lük } & \mathrm{H}_{3} \mathrm{BO}_{3}\end{array}$ uygulamalarının yararlı olabileceğini ortaya koymuştur.

\section{Teşekkür}

Bu çalışma Ç.Ü. Araştırma Projeleri Biriminin ZF2010YL73 Nolu Yüksek Lisans Projesinden Üretilmiştir.

\section{Kaynaklar}

Arrobas, M, Lopes JI, Pavão, F., Cabanas, J.E., Rodrigues, M.A. (2010) Comparative boron nutritional diagnosis for olive based on July and January leaf samplings. Commun. Soil Sci Plant Anal 41:709-720.

Aydın, N, Bayramoğlu, H, Mut, Z, Özcan, H . (2005) Ekmeklik Buğday Triticum aestivum L. Çeşit ve Hatlarının Karadeniz Koşullarında Verim ve Kalite Özelliklerinin Belirlenmesi . Journal of Agr Sci 11 (03):257-262.

Barton, C. J. (1948). Photometric analysis on phosphate rock. Ind. Anal. Eng. Chem. 20:1068-1073.

Batjer LP., Thompson, A H. (1949) Effect of Bor Acid Sprays Applied during Bloom upon The Set of Pear Fruits. Proceedings of the American Society for Hort Sci 53:141-142.

Bingham. F.T. (1982) Boron. In: Page. A.L., Miller. R.H., Keeney. D.R. (ed.) "Methods of Soil Analysis." Part 2. Madison. Pp: 431-447.

Bouyoucus. G.J. (1952) Arecalibration of hidrome analysis of soils. Agron. $J$ 43: 434-438.

Bremner. J. M. (1965) Method of soil analysis part 2. Chemical and Microbiological methods. American Society of Agro. Inc. Madison pp. :1149-1178.

Carson. P.L. (1980) Recommended potassium test. In: Recommended chemical soil test procedures for the North Central Region. Rev. Ed. North Central. Regional Publicaton no. 221. North Dakota Agric. 


\section{Artan Dozlarda Bor Uygulamasının İki Farklı Zeytin (Olea europaea L.) Çeşidinin Yaprak Bor Konsantrasyonu Üzerine etkisi}

Exp. Stn. North Dakota State University. FArgo USA. P: 20-21.

Çağlar, K.Ö. (1949) Toprak Bilgisi. A.Ü. Ziraat Fakültesi Yayınları: 10. Ankara.

Dridi J, Fendri M, Breton CM, Msallem M (2018) Characterization of olive progenies derived from a Tunisian breeding program by morphological traits and SSR markers. Scientia Horticulturae 236: 127-136.

Dursun, Ö. (2010) Yapraktan Kalsiyum ve Bor Uygulamalarının Ayvalık Yağlık Zeytin Ceşidinde Meyve Gelişmesi ve Kalitesi Üzerindeki Etkileri. Yüksek Lisans Tezi. Ege Üniversitesi Fen Bilimleri Enstitüsü. İzmir.

Eryüce, N. (1979) Ayvalık Bölgesi Yağlık Zeytin Çeşidi Yapraklarında Bazı Besin Elementlerinin Bir Vegetasyon Periyodu İçindeki Değişimleri. Ege Üniversitesi Fen Bilimleri Enstitüsü. Doktora Tezi. Bornova. İzmir.

FAO (2018) Food and Agriculture Organization of the United Nations (FAO). http://www.fao.org/

FAO (2019) Food and Agriculture Organization of the United Nations (FAO). http://www.fao.org/

Goldbach, H.E., Wimmer. M. (2007) Boron in plants and animals: is there a role beyond cell-wall structure? J. Plant Nutr. Soil Sci 170:39-48.

Gündeşli, M, Nikpeyma, Y. (2016) İlkbaharda Yapraktan Bor Uygulamasının Gemlik Zeytin Çeşidinde Meyve Tutumu Üzerine Etkisi. Meyve Bilimi 3 (2): 13-19.

Güneş, A, Gezgin, S, Kalinbacak, K, Özcan, H, Çakmak, I. (2017) Borun bitkiler için önemi. Journal of Boron, Agrobor özel say1s1: $168-174$.

Hanson, E.J. (1991) Sour cherry trees respond to foliar boron applications HortScience 26(9):1142-1145.

Hartmann, H.T., Uriu, K., Lilleland, O., (1966) Olive nutrition. In: Childers, N.F. (Ed.), Temperate to Tropical Fruit Nutrition. Hort. Publ. Rutgers Univ., New Brunswick, N.J, pp: 252-261

Jackson, M.L. (1962)Soil Chemical Analysis. Englewood Cliffs. New Jersey.
Kacar, B. ve İnal, A. (2010) Bitki Analizleri. Nobel Yayın No: 1241. Ankara.

Keleş Uzel, N, Çimrin, K. (2020) Gaziantep İli Nizip İlçesi Zeytin Bahçelerinin Yaprak ve Toprak Örnekleri ile Beslenme Durumunun Belirlenmesi. Kahramanmaraş Sütçü İmam Üniversitesi Tarım ve Doğa Dergisi 23 (4) :1039-1053

Larbi, A., Gargouri, K., Ayadi, M., Dhiab, A. B., \& Msallem, M. (2011) Effect of foliar boron application on growth, reproduction, and oil quality of olive trees conducted under a high density planting system. Journal of Plant Nutr 34(14):2083-2094.

Lindsay, W.L. ve Norvell, W.A. (1978) Development of DTPA soil test for zinc, iron, manganase and copper. Soil Sci. Soc. Am. J 42: 421-428.

MA Rodrigues, IQ Ferreira , AM Claro, M. Arrobas (2012) Fertiliser recommendations for olive based upon nutrients removed in crop and pruning. Sci. Hortic 142:205 - 211.

Marschner P. (2012) Marschner's Mineral Nutrition of Higher Plants, 3rd Ed. Amsterdam, Netherlands: Elsevier Academic Press pp: 684.

Mclean, E.O. (1982) Soil PH and Lime Requirement in Methods of Soil Analysis (A.L. Page et al. Ed.). Part II. 2nd. American Society of Agronomy Inc. Publisher. Madison. Wisconsin. U.S.A., p:199-224

Penca, S. Bellaloui, N., Greve, C., Hu, H., Brown. H. (2001a) Boron transport and soluble carbonhydrate in olive. J. Amer. Soc. Sci. 126(3):291-296.

Penca, S., Brown, P.H., Connell, J.H., Nyomora, A.M.S., Dardas, C., Hu, H. (2001b) Foliar boron application improves flower fertility and fruit set of olive HortScience 36 (4):714-716.

Perica,J., Brown, P.H., Connell,J.H., Hu, H., (2002) Olive response to foliar B application. Acta Hort 586:381-382.

Püskülcü, G. (1981) Memecik Zeytin Çeşidinde Makro ve Mikro Besin Elementlerinin Mevsimsel Değişimlerinin İncelenmesi. 


\section{Artan Dozlarda Bor Uygulamasının İki Farklı Zeytin (Olea europaea L.) Çeşidinin Yaprak Bor Konsantrasyonu Üzerine etkisi}

Ege Üniversitesi Fen Bilimleri Enstitüsü. Uzmanlık Tezi.

Razmioo, K. and Henderlong, P.R. (1997) Effect of potassium, sulfur, boron and molybdenum fertilization on alfalfa production and herbage macronutrient contents. Journal of Plant Nutrition 20:1681-1696.

Römheld, V. and Marschner, H. (1991) Functions of micronutrients in plants. In Micronutrients in Agriculture. 2nd edn. Eds. J J Mordvedt. F R Cox. L M Shuman and R M Welch. Pp: 297-328. SSSA Book Series. No. 4. Madison WI USA.

Olsen, S.R., Cole, C.V., Watanabe, F.S., Dean, L.A. (1954) Estimation of available phosphorus in soil by extraction with sodium bicarbonate. USDA Circ., 939. U.S. Cov. Print Office. Washington D.C.

Shorrocks, V.M. (1997) The occurrence and correction of boron deficiency. Plant Soil. 193:121-148.

Soyergin, S., (2010) Effects of Soil and Leaf Treatments to Eliminate Boron Deficiency in Olives. Commun. Soil. Sci. Plant Anal. 41(16):2004-2010.

Torun A, Duymuș E, Erdem H, Tolay I, Cenkseven Ş, Gülüt KY, Torun B. (2018) Determination of the effect of boron applications on salt damage in sunflower. Turkish Journal of Agriculture - Food Science and Technology 6 (12): 17811788.

Torun A, Sadettin Bozgeyik, Duymuş E. (2021) Artan Dozlarda Bor Uygulamasının Antep fistığ 1 (Pistacia vera L.) Çeşitlerinin Yeşil Aksam Bor Konsantrasyonu ve Diğer Besin Elementlerinin Alımı Üzerine Etkisi. Türk Tarım - Glda Bilim ve Teknoloji Dergisi Basımda.

The International Olive Council (IOC) (2019) http://www.internationaloliveoil.org/estat icos/view/224-testing-methods.Access date: 17 August 2019.

TUIKK (2019). Türkiye İstatistik Kurumu https://biruni.tuik.gov.tr/medas/?kn=92\& locale=tr, Erişim Tarihi: 25.03.2019
Wolf B (1971.) The Determination of Boron Soil Extracts, Plant Materials, Composts, Manure, Water and Nutrient Solutions. Soil Sci. And Plant Anal 2(5): 363-374. 
Artan Dozlarda Bor Uygulamasının İki Farklı Zeytin (Olea europaea L.) Çeşidinin Yaprak Bor Konsantrasyonu Üzerine etkisi 